\title{
Desafios da gestão escolar na construção da educação integral
}

\section{Challenges of school management in the integral construction of education Desafíos de la gestión escolar en la construcción de la educación integral}

PEDRO GANZELI

Orcid Id: http://orcid.org/0000-0002-6237-5110

Universidade Estadual de Campinas.

CRISTIANE MACHADO

Orcid Id: https://orcid.org/0000-0002-3522-4018

Universidade Estadual de Campinas

ROSANE GARCIA DORAZIO NOGUEIRA

Orcid ld: https://orcid.org/0000-0002-6079-9729

Universidade Estadual de Campinas

\begin{abstract}
Resumo: Este artigo tem o objetivo de explicitar e problematizar os desafios enfrentados e as ações adotadas pela gestão escolar para a construção da educação integral em uma escola municipal de Campinas-SP de ensino fundamental. Utilizamos como procedimentos metodológicos a revisão bibliográfica, a análise documental e observações participativas na unidade escolar pesquisada. O processo de organização do espaço escolar demandou embates políticos e pedagógicos entre as instâncias da Secretaria Municipal de Educação e a equipe gestora, prevalecendo as demandas da unidade escolar.
\end{abstract}

Palavras-chave: Educação integral. Escola em Tempo Integral; Gestão escolar. Projeto político-pedagógico.

Abstract: This article aims to explain and problematize the challenges faced and the actions adopted by the school management for the construction of full-time education in an elementary school in the city of São Paulo. We used as methodological procedures the bibliographic review, the documentary analysis, and participant observations on the researched school unit. The process of organizing the school space involves political and pedagogical conflicts between the instances of the Municipal Education Department and the management team, with the prevalence of demands of the school unit.

Keywords: Integral Education. Full-time education; School Management. PoliticalPedagogical Project. 
Resumen: Este articulo tiene como objetivo explicar y problematizar los desafios enfrentados y las acciones tomadas por la administración escolar para la construcción de la educación a tiempo completo en una escuela municipal de Campinas (SP) de educación primaria. Utilizamos como procedimientos metodológicos la revisión de literatura, análisis de documentos y observaciones participativas en la unidad escolar investigada. El proceso de organización del espacio escolar exigió enfrentamientos políticos y pedagógicos entre las instancias de la Secretaría Municipal de Educación y el equipo directivo, prevaleciendo las demandas de la unidad escolar.

Palabras clave: Educación integral. Educación a tiempo completo; Gestión escolar. Proyecto Político Pedagógico.

\section{INTRODUÇÃO}

Nos últimos anos, verificamos o aumento de políticas educacionais que promovem a ampliação do tempo de permanência dos estudantes na escola, demandando inovações na organização curricular na direção da educação integral (COELHO; HORA; ROSA, 2015). Dados divulgados pelo Instituto Nacional de Estudos e Pesquisas Anísio Teixeira - Inep (BRASIL, 2017) mostram que de 2010 a 2015 o número de matriculados mais que triplicou no período, passando de 1.327.129 para 4.648.277 de estudantes.

O Programa Mais Educação, criado em 2007 pelo governo federal, foi um indutor da ampliação da jornada do aluno de ensino fundamental no contraturno escolar em todo o Brasil (MAURÍCIO, 2014), favorecendo o debate sobre o significado da educação integral, considerando as limitações da organização da escola pública (LECLERC; MOLL, 2012). Algumas análises sobre esse programa indicam que suas diretrizes são "mercadológicas e gerenciais" e que a política "visa à racionalização dos gastos, à transferência de responsabilidades e à obtenção de melhores resultados" (SCHIMONEK, 2015, p. 513).

As experiências de educação em tempo integral podem ser agrupadas, em linhas gerais, em dois formatos, conforme indica Cavaliere (2009, p. 53): 1) enfatiza a ampliação do tempo de atividades dos alunos no âmbito da unidade escolar com vivências curriculares diversificadas sendo, portanto, "escola de tempo integral"; 2) busca utilizar o espaço do contraturno escolar com ações, "fruto da articulação com instituições multissetoriais, utilizando espaços e agentes que não os da própria escola, pretendendo propiciar experiências múltiplas e não padronizadas", se constituindo em "aluno em tempo integral". Coelho (2012, p. 81-82) explica que: 
[...] a primeira expressão - escola de tempo integral - compreende a ampliação da jornada como um fator demandado pela própria natureza e função da escola. Em outras palavras, se entendemos ser essa função a de apresentar, constituir e construir os conhecimentos sócio-historicamente consolidados, quanto maior for o tempo dedicado a esse processo, obviamente dentro de uma organização curricular própria à escola e a essa meta, além de presente no projeto pedagógico da instituição, maiores serão as possibilidades de que essa construção aconteça com qualidade. Já a segunda expressão - aluno em tempo integral - abre espaço não para o adensamento da função da escola, como a entendemos e evidenciamos [...], mas sim para o sujeito que nela se (con)forma: o aluno.

Ao mesmo tempo em que há um consenso de que as iniciativas de ampliação do tempo de permanência na escola têm se desenvolvido com base em diferentes modelos e organizações dos tempos e espaços, há também consenso da constante e robusta expansão dessas experiências, seja em uma perspectiva de democratização da educação básica (CAVALIERE, 2013), seja como forma de enfrentamento das desigualdades educacionais (CAVALIERE; MAURÍCIO, 2012), ou ainda como política compensatória com caráter provisório, pontual e temporário, aproximando-se do caráter filantrópico (CAVALIERE, 2014).

A transformação de uma unidade escolar que funcionava em tempo parcial para uma "escola de educação integral" compreende um desafio para os gestores educacionais dos órgãos centrais, assim como da unidade escolar envolvida, sendo considerado um processo que abrange a confluência, e não raro, o conflito, entre interesses e especificidades organizacionais que requerem estudos sobre o seu significado para o projeto político-pedagógico (PPP) instituído e instituinte na escola. Nesse sentido, concordamos com a compreensão de Coelho, Hora e Rosa (2015, p. 156) de que "tempo integral não corresponde, necessariamente, a educação integral", todavia, é possível aproximar esses conceitos por meio da organização curricular e pedagógica das experiências implementadas.

Para Silva (2018), as escolas que aderem às propostas educação integral e/ou em tempo integral precisam ter como princípio e horizonte a garantia dos direitos sociais a todas as crianças e jovens brasileiros para se tornarem:

Uma escola acolhedora e humanista, com professores e gestores qualificados e respeitados por condições de trabalho dignas, uma segura orientação curricular e pedagógica, uma prática de autonomia e de sustentabilidade, entre outras bandeiras, haveria de nuclear uma escola e uma educação integral para a humanização, para a cidadania, para a inclusão e para a plena vivência da diversidade humana. (SILVA, 2018, p. 123). 
Em janeiro de 2014, foi instituído o município de Campinas-SP o "Projeto Piloto "Escola de Educação Integral (EEI)", pelo decreto n ${ }^{\circ}$ 18.242. Nesse mesmo ano, duas unidades escolares foram transformadas em EEI e no ano de 2015, mais três unidades passaram a integrar o projeto piloto.

Este artigo ${ }^{1}$ tem o objetivo de explicitar e problematizar os desafios enfrentados e as ações adotadas pela gestão escolar para a construção da educação integral em uma escola da rede municipal de Campinas, que atende alunos de ensino fundamental. Utilizamos como procedimentos metodológicos, neste estudo: revisão bibliográfica, análise documental e observações participantes na unidade escolar pesquisada (SHIROMA; CAMPOS; GARCIA, 2005), ancorados no método da pesquisa-ação - mesma escolha teórico-metodológica da pesquisa mais ampla. De acordo com Barbier (2002, p. 119):

O espírito mesmo da pesquisa-ação consiste em uma abordagem em espiral que a todas utiliza. Significa que todo avanço em pesquisa-ação implica o efeito recursivo em função de uma reflexão permanente sobre a ação. Inversamente, porém, todo segmento de ação engendra ipso facto um crescimento do espírito da pesquisa.

A organização do trabalho de pesquisa envolve dois grupos de pesquisadores: os externos, provenientes da universidade e os internos, sujeitos que participam do dia a dia escolar e que se dispuseram à produção da pesquisa. Com o desenvolvimento da pesquisa, busca-se a formação de um "pesquisador coletivo", implicado na explicação da dinâmica da realidade investigada ${ }^{2}$. A participação de todos os pesquisadores (externos e internos) no processo de pesquisa, desde a produção do diagnóstico até a elaboração de relatórios, deve ser considerada como cogestão, que promove o desenvolvimento de explicações comuns sobre a realidade pesquisada. Para Morin (2004, p. 67), a participação "exige engajamento pessoal, abertura à atividade humana, sem relação de dependência, onde o diálogo prevalece nas relações de cooperação ou de colaboração."

Os dados para a elaboração deste artigo foram coletados no período de dezembro de 2017 a novembro de 2018, por meio de coleta de documentos e anotações em diário de campo realizadas em 16 reuniões entre a equipe de

1 Este artigo é resultado parcial da pesquisa "A construção da educação integral: projeto político pedagógico participativo e democrático”, com financiamento PROC. FAPESP 2017/14814-0, coordenada pelo Prof. Dr. Pedro Ganzeli.

2 Para Barbier (2002), o pesquisador coletivo é um grupo-sujeito formado por pesquisadores profissionais, no caso, dois professores universitários (Prof. Dr. Pedro Ganzeli e Prof ${ }^{a}$. Dr ${ }^{a}$. Cristiane Machado) e por membros "que gozem de todos os privilégios (mas particularmente implicados), da população vinculada à investigação participativa" (p. 103), no caso, a diretora e as duas orientadoras pedagógicas (Prof ${ }^{2}$. Rosane Garcia Dorazio Nogueira, Prof ${ }^{a}$. Andréia dos Anjos Cassado e Prof ${ }^{a}$. Carolina da Silva Costa). 
pesquisadores (externos e internos - as informações sobre os participantes foram excluídas do texto para avaliação garantindo o anonimato), no acompanhamento das atividades realizadas para a construção do Projeto Político-Pedagógico da Escola de Educação Integral.

Considerando as determinações da política de educação integral como produção de regras para serem realizadas no âmbito das unidades escolares, cabe analisar os processos que envolveram a concretização da política, na perspectiva do modelo organizacional em ação (LIMA, 2001). Assim, inicialmente apresentamos as orientações previstas na legislação sobre a educação integral na rede municipal de educação de Campinas para, em seguida, analisarmos o processo vivenciado por uma unidade escolar da rede municipal, com foco no trabalho desenvolvido pela equipe gestora, a fim de atender as demandas administrativas e políticopedagógicas para a transformação da escola parcial em integral.

\section{PRECEITOS CONSTITUCIONAIS E PROJETO PILOTO DA ESCOLA DE EDUCAÇÃO INTEGRAL DA REDE MUNICIPAL DE ENSINO}

A construção do conceito de educação integral passa necessariamente, a nosso ver, pelas disposições expressas na Constituição Federal e da legislação que a regulamenta, bem como no movimento político administrativo que informa a organização da educação no Brasil.

A Constituição da República Federativa do Brasil, de 5 de outubro de 1988, garantiu a educação enquanto direito, sendo essa disposição de fundamental importância para a construção de uma realidade educacional que contribua para a superação das desigualdades sociais, econômicas e políticas presentes no nosso país. O artigo 205 da Constituição Federal define a educação como:

[...] direito de todos e dever do Estado e da Família, será promovida e incentivada com a colaboração da sociedade, visando ao pleno desenvolvimento da pessoa, seu preparo para o exercício da cidadania e sua qualificação para o trabalho. (BRASIL, 1988).

Dessa forma, compreendemos que uma educação baseada nesses princípios constitui a educação republicana ${ }^{3}$ e, para sua construção, é necessário um projeto político-pedagógico que promova a educação em sua integralidade.

3 Compreendemos educação integral como um conceito para além de programas e/ou modalidades de ensino, identificando-a com a educação republicana, em conformidade com os determinantes constitucionais. Consideramos que o atendimento aos interesses sociais e individuais pela educação integral se faz indispensável para superação da formação de deficientes cívicos (SANTOS, 1999). 
Assim, podemos considerar a "educação integral" como uma expressão da educação republicana, conforme disposto no texto constitucional (GANZELI, 2018).

Entretanto, a Lei de Diretrizes e Bases da Educação Nacional ( $\mathrm{n}^{\circ}$ 9.394/1996) é genérica sobre a organização escolar para a garantia da educação integral. A legislação mostrou-se mais específica ao definir o número de horas mínimas de frequência diária à escola na educação infantil e ensino fundamental. No artigo 29, que trata do atendimento na educação infantil, verificamos a distinção entre o período de permanência do estudante na escola, sendo o mínimo de 4 (quatro) horas diárias, considerado turno parcial e de 7 (sete) horas diárias para a “jornada integral”. A legislação determina que no ensino fundamental o estudante tenha que cumprir "pelo menos" 4 (quatro) horas diárias no estabelecimento de ensino, "sendo progressivamente ampliado o período de permanência na escola" (Art. 34).

Em 2007, por meio da Portaria Interministerial no 17/2007, o governo federal instituiu o Programa Mais Educação com o propósito de criar as condições para a ampliação da jornada escolar, prioritariamente, em escolas com baixo Índice de Desenvolvimento da Educação Básica (Ideb) e localizadas em regiões de vulnerabilidade social. O Art. $1^{\circ}$ explicita o objetivo do programa de:

[...] contribuir para a formação integral de crianças, adolescentes e jovens, por meio da articulação de ações, de projetos e de programas do Governo Federal e suas contribuições às propostas, visões e práticas curriculares das redes públicas de ensino e das escolas, alterando o ambiente escolar e ampliando a oferta de saberes, métodos, processos e conteúdos educativos. (BRASIL, 2007).

Cabe pontuar que estudos formularam críticas ao programa como a pouca integração entre as atividades desenvolvidas pelos voluntários do Programa Mais Educação e o projeto político-pedagógico da unidade escolar. Para Cavaliere (2014), esse programa promoveu a ampliação junto a determinados grupos de alunos de atividades de diferentes naturezas não promovendo a educação de forma integral. Mesmo tendo o mérito de proporcionar a superação do caráter disciplinar presente no espaço escolar, as atividades propostas consistiram em "justaposição à rotina escolar de atividades complementares, chamadas de 'atividades de educação integral'." (p. 1214). A autora afirma, ainda, que o Programa Mais Educação ${ }^{4}$, em consequência de seu caráter compensatório, não

4 Em 2016, o Programa Mais Educação foi substituído pelo Programa Novo Mais Educação, direcionado para as escolas de ensino fundamental, com foco no ensino de língua portuguesa e matemática, conforme disposições da portaria $\mathrm{n}^{\circ} 1.144$, de 10 de outubro de 2016 . O fomento às escolas de tempo integral foi normatizado pela portaria $n^{\circ} 1.145$, direcionando-se para as escolas de ensino médio. 
garantiu a promoção da educação integral considerada como "a formação do indivíduo em seus aspectos cognitivos, culturais, éticos, estéticos e políticos." (CAVALIERE, 2014, p. 1214).

Com a lei $\mathrm{n}^{\circ} 13.005$, em 25 de junho de 2014, que aprova o Plano Nacional de Educação - PNE (2014/2024), o debate sobre a oferta de educação integral foi revigorado, prevendo em sua meta 6, para o final da década: “oferecer educação em tempo integral em, no mínimo, 50\% (cinquenta por cento) das escolas públicas, de forma a atender, pelo menos, $25 \%$ (vinte e cinco por cento) dos(as) alunos(as) da educação básica.”

No Plano Municipal de Educação - PME (2015/2025) do município de Campinas (lei $\mathrm{n}^{\circ} 15.029$, de 24 de junho de 2015), a meta 6 reproduz o texto do PNE (2014/2024). Suas sete estratégias apresentam-se semelhantes ao texto do plano nacional, das quais destacamos três:

6.6 - Criar subsídios e viabilizar construção curricular nas escolas de Educação Integral que garanta a permanência dos alunos em jornada ampliada, contemplando as múltiplas dimensões formativas dos sujeitos, sem hierarquização e fragmentação das diferentes áreas do conhecimento no espaço e tempo curricular;

6.7 - Assegurar jornada adequada ao trabalho pedagógico das escolas de Educação Integral a todos os profissionais;

6.8 - Garantir estudo e ações que limitem o número de alunos por professor. Que a relação professor/aluno seja definida por etapa, considerando as seguintes diretrizes:

a) para o ensino fundamental, anos iniciais: $20 / 25$ estudantes por turma;

b) para o ensino fundamental, anos finais: 25/30 estudantes por turma.

Evidencia-se nessas estratégias a preocupação dos proponentes sobre a organização do espaço escolar, dos componentes curriculares, do trabalho docente e da relação aluno/turma, de forma a viabilizar um atendimento qualificado nas "Escolas de Educação Integral", aproximando-se da concepção de "educação integral" e afastando-se da concepção de "aluno em tempo integral", na qual existe um aumento nas atividades curriculares no contraturno do aluno, sem alterações no currículo escolar parcializado, conforme analisamos anteriormente (CAVALIERE, 2009; COELHO, 2012).

Em janeiro de 2014, antecipando o PME, foi instituído pelo decreto $\mathrm{n}^{\circ}$ 18.242 o "Projeto Piloto 'Escola de Educação Integral (EEI)", sendo criada uma comissão para a definição de suas diretrizes. $\mathrm{O}$ artigo $3^{\circ}$ determina que: 
Os alunos das unidades educacionais nas quais for implantado o Projeto Piloto "Escola de Educação Integral - EEI" passarão a ter, no mínimo, 07 (sete) horas de permanência diária na escola, podendo totalizar o máximo de 45 (quarenta e cinco) horas-aula semanais entre os componentes curriculares da Base Nacional Comum e das Atividades Complementares.

Para os professores foi criada uma jornada de trabalho específica, conforme analisaremos mais adiante, garantindo a sua permanência em uma única unidade escolar.

A normativa determinou que os componentes curriculares, tempos e espaços pedagógicos da EEI deveriam ser organizados por eixos de trabalho, definidos pelos órgãos colegiados das unidades educacionais e das equipes educativas dos órgãos descentralizados da Secretaria Municipal de Educação (SME) de Campinas, sendo devidamente publicados em resolução.

Nesse mesmo mês e ano, a Comissão para Estudos da Escola de Educação Integral elaborou o documento "Projeto Piloto para Escola de Educação Integral: uma proposta em construção no município de Campinas" ${ }^{5}$ que comporta os fundamentos, concepção de educação integral, objetivos educacionais, diretrizes para a organização curricular, organização do trabalho docente, entre outros elementos constituintes da EEI no município.

Ao discutir os fundamentos das EEIs, o projeto piloto indica a importância do aumento do tempo de permanência do aluno em atividades educativas, entretanto, afirma a necessidade de qualificação e articulação destas, com a elaboração de projeto interdisciplinar exigindo a reformulação do projeto de escola para a formação integral do aluno.

O documento explicita que a organização do ensino nas EEIs deve ser realizada numa "perspectiva articulada, integrada e interdisciplinar", tendo por base "Eixos de Trabalho". Para tanto, todos os componentes curriculares passaram a ter a mesma carga didática, de forma a garantir a coerência entre os diversos componentes curriculares e as práticas sociais. Essas novas exigências demandou mudanças significativas na organização político-pedagógicas das unidades escolares participantes do projeto piloto, conforme analisaremos mais adiante.

O projeto piloto faz referência às "Diretrizes Curriculares Nacionais Gerais" (CNE/CEB nº7/2010) e às "Diretrizes Curriculares da Educação Básica para o Ensino Fundamental - Anos Iniciais: um processo contínuo de reflexão e ação" (2012) da rede municipal de educação de Campinas, como norteadoras do processo de organização curricular. Além disso, define o coletivo de professores, 
assim como a comunidade, como os principais responsáveis pela elaboração dos temas, conteúdos e formas de trabalho, garantindo a autonomia ${ }^{6}$ dos sujeitos na construção de um projeto político-pedagógico próprio da unidade escolar.

Para Ezpeleta e Rockwell (1986), a escola não pode ser compreendida apenas enquanto versão presente nos registros oficiais (normativas, diretrizes curriculares, avaliação externas, outras), mas também como uma realidade não documentada, considerando que "a determinação e presença estatal se entrecruza com as determinações e presenças civis de várias características.” (p. 13). É nessa direção que, a seguir, apresentamos o processo de construção da educação integral em uma unidade escolar da rede municipal de Campinas, tendo como foco a organização do espaço escolar e sua relação com o projeto político-pedagógico.

\section{DESAFIOS DA ORGANIZAÇÃO DA ESCOLA DE EDUCAÇÃO INTEGRAL}

A complexidade do cotidiano escolar apresenta inúmeros desafios para gestores, funcionários e docentes. Nos limites deste artigo, destacaremos dois desafios que se mostraram relevantes no processo de transformação da escola de tempo parcial em uma escola de educação integral: adequação dos espaços/ tempos escolares.

A unidade escolar em que realizamos a pesquisa foi inaugurada no ano de 1968, recebendo o nome de Escola Parque Raul Pila (NOBRE, 2008). Com projeto inovador, suas instalações contavam com piscina, teatro de arena, sala de artes, salas de aula, pátios e salas de administração, em terreno amplo com 10 mil $\mathrm{m}^{2}$, atendendo alunos do pré-primário ao primário.

O espaço escolar foi sendo transformado conforme as demandas sociais e econômicas do município, assim como para atendimento das reformas educacionais. Em 2014, a então Escola Municipal de Ensino Fundamental Raul Pila, atendia a aproximadamente 610 alunos, do $1^{\circ}$ ao $9^{\circ}$ ano, organizados em dez turmas no período manhã e oito no período da tarde, contando com 80 matrículas na Educação de Jovens e Adultos (EJA) no período noturno. Suas instalações compreendiam dez salas de aula, uma biblioteca, uma sala multiuso, um laboratório de informática e duas quadras poliesportivas sem cobertura. A equipe gestora era composta por uma diretora, duas vice-diretoras, dois orientadores pedagógicos. O quadro de professores era formado por 33 docentes, contando com 15 funcionários. 
O início do ano letivo de 2014 na EMEF Raul Pila foi marcado por um comunicado do Núcleo de Ação Educativa Descentralizada (NAED), órgão descentralizado da SME de Campinas, informando que a partir do próximo ano a unidade escolar passaria a atender a educação integral. Entre as justificativas para a instalação da educação integral, destacava-se: amplo espaço físico, equipe de gestão escolar completa, baixo rendimento pelo Ideb e atendimento a uma população em condições de vulnerabilidade social.

A transformação da unidade escolar em educação integral foi recebida com reserva pela equipe gestora, pois não havia sido feita nenhuma consulta prévia. Além disso, desde o ano de 2012, quando a diretora em exercício assumiu o cargo ${ }^{7}$, um conjunto de ações foi realizado no sentido de qualificar o projeto políticopedagógico. No ano de 2013, por exemplo, contou com o desenvolvimento de 20 oficinas pedagógicas com o aporte do Programa Mais Educação. A comunidade contava, ainda, com o apoio de duas organizações filantrópicas no bairro para o atendimento no contraturno, indicando a existência de atividades extraescolares para os alunos da unidade escolar.

A notícia da transformação da escola em educação integral foi recebida com ceticismo pelos professores e funcionários, preocupados com as possíveis dificuldades que as mudanças poderiam gerar. Informações como a inadequação do espaço físico e as dificuldades com a organização do trabalho docente, advindas das duas primeiras escolas de educação integral em atividade naquele ano, influenciavam negativamente a percepção deles sobre a escola de educação integral.

A comunidade de pais e responsáveis avaliou com otimismo a transformação da escola em educação integral, considerando positiva a possibilidade de suas filhas e filhos estenderem a permanência na escola, compreendida como ampliação de possibilidades de aprendizagem.

Iniciou-se um diálogo entre a equipe gestora e os dirigentes da SME, tendo como foco a inadequação das instalações para o atendimento à educação integral, considerando a questão: como atender 18 turmas em 10 salas ao longo da jornada integral?

Foi cogitada a incorporação da biblioteca, laboratório de informática e da sala de multiuso como salas de aula, sendo verificada a possibilidade de construção de dois "quiosques" no espaço escolar para o atendimento de turmas. Essas sugestões foram rejeitadas pela equipe gestora, com a justificativa que

7 Entre os anos de 2002 a 2012 ocorreu a alteração de dez diretoras à frente da gestão dessa unidade escolar, demonstrando a instabilidade nos processos de organização da unidade nesse período. 
seria um grande prejuízo para a dinâmica curricular, bem como, a experiência com quiosques nas unidades escolares de educação integral não tinha sido bem avaliada, especialmente em dias de chuva.

Em abril de 2014, diante da resistência e dificuldades demonstradas, os dirigentes sugeriram que a equipe de gestão apresentasse uma proposta de adequação do espaço físico com o "mínimo indispensável" para o atendimento da educação integral. Este foi o primeiro desafio da equipe gestora, que passou a realizar estudos sobre as instalações necessárias para o atendimento da educação integral. O estudo envolveu um processo de análise e negociação entre a equipe gestora, funcionários do departamento de arquitetura da SME, tendo como foco a adequação qualificada do espaço escolar.

As sugestões de mudanças apresentadas ao Conselho de Escola versavam sobre a necessidade de construção de um novo refeitório com capacidade para 250 pessoas, viabilizando o atendimento de todos os alunos em apenas dois momentos; construção de cozinha, despensa, banheiro e vestiário para cozinheiras, de forma a garantir a produção de alimentos em condições adequadas de higiene, assim como a construção de mais quatro salas de aulas. Os debates foram pautados pela necessidade de atendimento condizente com o previsto na Constituição, no qual o espaço físico deveria garantir o atendimento humanizado e humanizador das pessoas. Após a aprovação da proposta pelo Conselho de Escola, esta foi encaminhada para análise dos órgãos centrais.

Em maio de 2014, a proposta de construção foi aprovada, sendo autorizado o uso de recursos destinados à unidade escolar para a realização das obras, agilizando o processo de construção e as obras iniciadas em agosto. A empresa construtora garantiu a realização das obras com a disponibilização de duas equipes, possibilitando a entrega das novas edificações no mês de novembro. A aquisição do mobiliário demandou novas negociações com os órgãos centrais e a instalação ocorreu apenas no início do ano letivo.

Nos meses seguintes, foram feitas adaptações no espaço escolar com a verba do Programa Conta Escola ${ }^{8}$ : o antigo refeitório tornou-se uma biblioteca, a antiga cozinha tornou-se sala de Arte, a antiga biblioteca e o almoxarifado tornaram-se salas de aula.

O segundo desafio foi a organização dos tempos/espaços pedagógicos de professores e alunos da escola de educação integral. Ao longo do segundo semestre de 2014, equipe gestora passou a estudar em conjunto com o corpo

8 O Programa Conta Escola da Secretaria Municipal de Campinas foi criado com o objetivo de repassar recursos financeiros para as unidades escolares da rede (decreto no 14.524 , de 14 de novembro de 2003). 
docente, a composição da nova matriz curricular para o período estendido. Um dos múltiplos aspectos envolvidos estava na transformação da organização disciplinar em dois turnos de 4 horas diárias (manhã e tarde) e 30 horas/aulas semanais, para uma estrutura curricular que deveria atender a jornada única de 7 horas diárias e 45 horas semanais.

Atendendo a diretriz do Projeto Piloto da não hierarquização das disciplinas, todos os componentes curriculares passaram a ter a mesma carga didática, com 6 horas/aulas, sendo uma inovação na organização da grade de horários, exigindo adaptações ao longo de dois anos.

A jornada de trabalho docente também foi alterada, pois até então compreendia três possibilidades de composição, a saber: 15/20, 24/32, 30/40, sendo que o primeiro número representa a quantidade de horas/aulas destinadas a atividades com os alunos e as demais divididas em atividades de atendimento escolar e planejamento pedagógico. Nas escolas de educação integral foi criada a jornada 24/40. A jornada de trabalho docente foi organizada da seguinte forma:

I - Trabalho Docente com Aluno (TDA): compreende o exercício da docência em cumprimento ao currículo, em atividade direta com a coletividade de crianças, adolescentes;

II - Horas-atividade: de cumprimento obrigatório para todos os docentes, inclusive aos que se encontrem em regime de acumulação de cargos, formada por:

a) Trabalho Docente Coletivo (TDC): espaço formativo que compreende reuniões pedagógicas da equipe escolar para a construção, o acompanhamento e a avaliação do PPP da Unidade Educacional e para as atividades de interesse da Secretaria Municipal de Educação;

b) Trabalho Docente Individual (TDI): para o Ensino Fundamental: compreende o atendimento e a recuperação dos alunos, reuniões com pais, atividades educacionais e culturais com alunos;

c) Trabalho Docente de Preparação de Aulas (TDPA): compreende o trabalho desempenhado em hora e local de escolha do docente, destinado à preparação das atividades pedagógicas;

d) Trabalho Docente entre Pares (TDEP): compreende as reuniões entre os docentes do mesmo Ciclo/Ano e ou Componente Curricular, para planejamento e organização do trabalho pedagógico;

e) Trabalho Docente de Formação (TDF): compreende o tempo utilizado pelos docentes para formação em serviço, objetivando à qualificação da ação pedagógica. (Resolução SME no 5/2014, Art. 5).

Organizar o trabalho pedagógico nesse novo formato, considerando os tempos/espaços estendidos das atividades pedagógicas, demandou um processo de estudo e negociações entre a supervisão escolar, a equipe de gestão, os professores, funcionários, alunos e pais/responsáveis dos alunos. 
A elaboração da grade curricular teve como preocupação central a distribuição dos diferentes componentes curriculares de forma a evitar a concentração de atividades em um único período, favorecendo a compreensão sobre o atendimento em período estendido. Foi necessário um trabalho intenso para a mudança da cultura escolar pautada no tempo parcial, para a ideia de educação integral. Não foi um processo sem conflito, pois não existia consenso entre gestores e professores sobre o significado da educação integral, evidenciando a necessidade da construção de uma concepção comum de educação integral entre os participantes do cotidiano escolar.

Com as alterações no espaço físico a unidade escolar passou a contar com 17 salas de aula para as 18 turmas. Uma nova dinâmica de utilização do espaço escolar foi elaborada, sendo estabelecida uma sala de referência para cada turma dos Ciclos I e II (do $1^{\circ}$ ao $5^{\circ}$ ano) e sala ambiente para as disciplinas dos Ciclos III e IV (do $6^{\circ}$ ao $9^{\circ}$ ano), com a utilização das quadras pela disciplina de Educação Física. O sistema de mudança de salas entre os alunos favoreceu formas diferenciadas no uso do espaço escolar, promovendo a circulação dos alunos e novas formas de apropriação do espaço coletivo neste ambiente. No ano de 2015, quando a unidade escolar passou a funcionar como Educação Integral, estavam matriculados 580 alunos, com um quadro de 52 professores 23 funcionários.

Houve renovação do quadro de professores, com a mudança de 50\% dos docentes, exigindo retomada das discussões sobre o significado da educação integral nas reuniões pedagógicas. Assim também foi alterada a equipe gestora, com a saída dos dois orientadores pedagógicos (OPs), queassim como os professores que solicitaram a saída, demonstraram descrença em relação a forma de organização da EEI. Os cargos de OPs só foram preenchidos no mês de setembro daquele ano, exigindo desdobramento no trabalho da diretora e das vice-diretoras para o acompanhamento pedagógico junto aos professores e alunos.

Foi fundamental para o exercício de organização curricular da escola em tempo integral a participação de todos os profissionais - professores e gestores - nas discussões e decisões relacionadas. Não foi um processo sem conflito, mas o resultado, ainda que não seja o ideal, promoveu um caminhar na direção de um projeto político-pedagógico que compreende o pleno desenvolvimento da pessoa, o exercício da cidadania e a qualificação para o mundo do trabalho.

O espaço escolar, enquanto construto cultural e histórico, compreende o suporte físico da educação, conforme o projeto que o sustenta. Alterada a função da escola, altera-se a forma de conceber sua arquitetura, suas instalações e, consequentemente, seu currículo e seus professores (DÓREA, 2013). O estudo 
revelou um processo em construção, no qual a transformação do espaço escolar foi acompanhada com a projeção de sua ocupação pedagógica na perspectiva da educação republicana.

\section{REFLEXÕES FINAIS}

Neste estudo, buscamos ressaltar a complexidade que envolveu o processo inicial (em construção) vivenciado em uma unidade escolar de ensino fundamental de escola de tempo parcial para uma escola de educação integral: determinações dos órgãos centrais; financiamento; estudos sobre a ocupação político-pedagógica do espaço escolar; dissensos e consensos entre equipe gestora, professores, funcionários, pais e alunos; que nos permite reafirmar que a administração escolar materializa-se pela interação entre os sujeitos (LIMA, 2001; PARO, 2007).

Os desafios de adequação do espaço físico e dos tempos pedagógicos para a escola de educação integral envolveram trabalho coletivo de estudo e planejamento político-pedagógico, produzindo uma identidade coletiva, ainda que precária, entre os sujeitos que vivenciaram o processo em construção. A organização dos tempos pedagógicos entre componentes curriculares com mesma carga didática, distribuídos ao longo da semana, sem hierarquização, com aulas no período da manhã e da tarde, exigiu a reformulação dos planos de ensino, das formas de relacionamento entre gestores, professores, funcionários, alunos, pais e comunidade, promovendo um aprendizado organizacional e transformando a forma de compreensão dos sujeitos sobre o significado da escola pública.

Acertos e erros passaram a ser foco de estudo e planejamento coletivo, tendo a gestão democrática como alicerce organizacional e como norte a construção de uma concepção comum de educação integral, respaldado no pluralismo de ideias em diálogo na EEI.

Cabe destaque a postura democrática assumida pela diretora escolar, ao garantir a participação nos encaminhamentos demandados, assim como tomou para si a tarefa de coordenação do processo de organização político-pedagógica da escola de educação integral e e da elaboração do PPP.

A construção da educação integral impõe desafios nas dimensões política, pedagógica e administrativa, as quais compreendem a organização da escola pública. Diante desses desafios, o princípio constitucional da gestão democrática tornou-se uma referência importante no processo de negociação e proposição de ações qualificadas e relevantes. 
$\mathrm{Na}$ experiência da Escola de Educação Integral Raul Pila o diálogo se apresentou como elemento fundante, como pavimento "do caminho que se faz ao caminhar" no processo de materialização da educação integral. Novos desafios, novas leituras...

\section{REFERÊNCIAS}

BARBIER, René. A pesquisa-ação. Brasília: Plano Editora, 2002.

BRASIL. Constituição da República Federativa do Brasil. Promulgada em 5 de outubro de 1988. Brasília, DF, 1988. Disponível em: https://goo.gl/oFsgfY. Acesso em: 12 abr. 2016.

BRASIL. Lei $\mathbf{n}^{\mathbf{0}}$ 9394, de 20 de dezembro de 1996. Estabelece as diretrizes e bases da educação nacional. Brasília, DF, 1996. Disponível em: https://goo.gl/ sDBLxD. Acesso em: 23 abr. 2015.

BRASIL. MEC. Portaria Normativa Interministerial $n^{\circ} 17$. Institui o Programa Mais Educação, que visa fomentar a educação integral de crianças, adolescentes e jovens, por meio do apoio a atividades sócio-educativas no contraturno escolar. Brasília, DF, 24 abr. 2007.

BRASIL. Lei $\mathbf{n}^{\mathbf{0}} \mathbf{1 3 . 0 0 5}$, de 25 de junho de 2014. Aprova o Plano Nacional de Educação - PNE e dá outras providências. Brasilia, DF, 2014. Disponível em: https://goo.gl/d4gBHi. Acesso em: 11 nov. 2014.

BRASIL. Ministério da Educação. Instituto Nacional de Estudos e Pesquisas Anísio Teixeira (Inep). Censo escolar 2016: notas estatísticas. Brasília, DF. 2017.

BRASIL. Ministério da Educação. Conselho Nacional de Educação. Câmara de Educação Básica Resolução $\mathbf{n}^{\mathbf{0}}$ 7, de 14 de dezembro de 2010. Fixa Diretrizes Curriculares Nacionais para o Ensino Fundamental de 9 (nove) anos. Brasília, DF, 2010.

BARROSO, João. O reforço da autonomia das escolas e a flexibilização da gestão escolar em Portugal. In: FERREIRA, N. S. C. (org.). Gestão Democrática da educação: atuais tendências, novos desafios São Paulo: Cortez, 1998. 
CAMPINAS. Secretaria Municipal de Educação. Diretrizes Curriculares da Educação Básica para o Ensino Fundamental - Anos Iniciais: Um processo Contínuo de Reflexão e Ação Prefeitura Municipal de Campinas. Organização e coordenação: Heliton Leite de Godoy. 2012.

CAMPINAS. Secretaria Municipal de Educação. Resolução n $\mathbf{n}^{\mathbf{5}}$, de 10 de março de 2014. Dispõe sobre a Organização do Trabalho Pedagógico das Unidades Educacionais integrantes do Projeto Piloto "Escola de Educação Integral - EEI".

CAMPINAS. Decreto $\mathbf{n}^{\mathbf{0}} \mathbf{1 8 . 2 4 2}$, de 24 de janeiro de 2014. Dispõe sobre a criação do Projeto Piloto de Escolas de Educação Integral (EEI) da rede pública municipal de ensino de Campinas e dá outras providências.

CAMPINAS. Decreto $\mathbf{n}^{\mathbf{0}} \mathbf{1 4 . 5 2 4}$, de 14 de novembro de 2003. Dispõe Sobre os critérios e normas para o repasse de recursos financeiros às Unidades Educacionais Públicas Municipais e revoga o Decreto No 13.854 De 15 De Fevereiro De 2002, Disponível em: https://url.gratis/HWwck. Acesso em 20 de fev 2017.

CAMPINAS. Lei Municipal $\mathbf{n}^{\mathbf{0}} \mathbf{1 5 . 0 2 9}$, de 24 de junho de 2015, Institui o Plano Municipal de Educação, na conformidade do artigo $6^{\circ}$ da Lei $n^{\circ} 12.501$, de 13 de março de 2006, do Município de Campinas, Estado de São Paulo.

CAVALIERE, Ana Maria. Escolas de tempo integral versus alunos em tempo integral. Revista Em Aberto, v. 22, n. 80, p. 51-63, abr. 2009.

CAVALIERE, Ana Maria; MAURÍCIO, Lucia Velloso. A ampliação da jornada escolar nas regiões Nordeste e Sudeste: sobre modelos e realidades. Revista Educação em Questão, Natal, v. 42, n. 28, p. 251-273, jan./abr. 2012.

CAVALIERE, Ana Maria; Educação integral como "política especial” na educação brasileira. In: COELHO, L. M. C. da C. (Org.). Educação integral: história, políticas e práticas. Rio de Janeiro: Rovelle, 2013. p. 237-254.

CAVALIERE, Ana Maria. Escola pública de tempo integral no Brasil: filantropia ou política de Estado? Educação \& Sociedade, Campinas, v. 35, n. 129, p. 12051222, out./dez. 2014. 
COELHO, Ligia Martha C. da C. Alunos no ensino fundamental, ampliação da jornada escolar e educação integral. Educar em Revista, Curitiba, p. 73-89, jul./ set. 2012.

DÓREA, Célia Rosangela Dantas. A arquitetura escolar como objeto de pesquisa em História da Educação. Educ. rev., Curitiba, n. 49, p. 161-181, set. 2013. Disponível em: https://goo.gl/K1TMqg. Acesso em: 23 maio 2015.

EZPELETA, Justa; ROCKWELL, Elsie. Pesquisa participante. São Paulo: Cortez: Autores Associados, 1986.

GANZELI, Pedro. Educação integral: direito público subjetivo. Educação: Teoria e Prática, v. 27, n. 56, p. 575-591, mar. 2018. Disponível em: https://goo. gl/AEVCPN. Acesso em: 17 maio 2018.

COELHO, Lígia Martha Coimbra da Costa; HORA, Dayse Martins; ROSA, Alessandra Victor. Organização curricular e escola de tempo integral: Precisando um conceito e(m) sua(s) práticas(s). Revista Teias, v. 16. n. 40, p. 155-173, 2015.

LECLERC, Gesuína de Fátima; MOLL, Jaqueline. Educação integral em jornada diária ampliada: universalidade e obrigatoriedade? In: Em Aberto Brasília, Instituto Nacional de Estudos e Pesquisas Educacionais Anísio Teixeira, v. 25, n. 88, p. 1-214, jul./dez. 2012.

LIMA, Licínio. A escola como organização educativa São Paulo: Cortez, 2001.

MAURÍCIO, Lucia Velloso. Ampliação da jornada escolar: configurações próprias para diferentes contextos - Brasil e Europa. Ensaio: aval. pol. públ. Educ., Rio de Janeiro, v. 22, n. 85, p. 875-898, out./dez. 2014.

MORIN, André. Pesquisa-ação integral e sistêmica: uma antropopedagogia renovada. Rio de Janerio: DP\&A, 2004.

NOBRE, Sonia Aparecida dos Santos. EMEF Raul Pila 1968-2008: 40 anos contribuindo para a educação de Campinas. Campinas, 2008.

PARO, Vitor Henrique. Gestão escolar, democracia e qualidade de ensino São Paulo: Ática, 2007. 
SANTOS, Milton. Os deficientes cívicos. Folha de São Paulo, São Paulo, 24 jan. 1999. Caderno Mais.

SCHIMONEK, Elisangela Maria Pereira. A qualidade do ensino público e a privatização via Programa Mais Educação. Educação: Teoria e Prática, Rio Claro, v. 25, n. 50, maio/ago. 2015.

\section{SILVA, Maria Cristiani G. A educação integral na escola de tempo integral:} as condições históricas, os pressupostos filosóficos e a construção social da política de Educação Integral como direito no Brasil. 2018. Tese (Doutorado em Educação) - Unicamp, Campinas, 2018. 146 f.

SHIROMA, Eneida Oto; CAMPOS, Roselane Fátima; GARCIA, Rosalba Maria Cardoso. Decifrar textos para compreender a política: subsídios teóricometodológicos para análise de documentos. Perspectiva, Florianópolis, v. 23, n. 2, p. 427-446, jan. 2005. Disponível em: https://goo.gl/hhRZE9. Acesso em: 2 maio 2014.

\section{Pedro Ganzeli}

Doutor em Educação. Professor Livre Docente da Faculdade de Educação da Universidade Estadual de Campinas. Departamento de Política, Administração e Sistemas Educacionais (DEPASE), coordenador do Laboratório de Gestão Educacional (LAGE). E-mail: pedro.ganzeli@gmail.com

\section{Cristiane machado}

Docente no Depase (Departamento de Políticas, Administração e Sistemas Educacionais) na Faculdade de Educação da UNICAMP - Universidade Estadual de Campinas. Doutora em Educação pela Faculdade de Educação da USP - Universidade de São Paulo (2003), Mestre em Educação pela Faculdade de Educação da UNICAMP - Universidade Estadual de Campinas (1995) e Bacharel e Licenciada em Ciências Sociais pela PUC Campinas - Pontifícia Universidade Católica de Campinas (1991). Desenvolve pesquisas relacionadas aos temas Política Educacional, Gestão Educacional e Avaliação Educacional. E-mail: crimacha@unicamp.br

\section{Rosane Garcia Dorazio Nogueira}

Mestranda na Faculdade de Educação da Universidade Estadual de Campinas - UNICAMP. Diretora Educacional de Escola Municipal de Campinas (SME). Membro do Laboratório de Gestão Educacional (LAGE). E-mail: rosanedorazio@uol.com.br 